\title{
A Comparative Study of Pedicled Versus Skeletonized Left Internal Mammary Artery Harvesting Techniques Regarding Rate of Mediastinitis Post CABG in Diabetic Patients \\ Waleed Abbas Kamel*, Sherif Ahmed Kamal Elhendawy \\ Department of Cardiac Surgery, National Heart Institute, Egypt \\ * Correspondence author: Waleed Abbas Kamel, Mobile: (+20)01000251414, Email: dr.waleedk@ yahoo.com
}

\begin{abstract}
Background: For grafting the left anterior descending (LAD) coronary artery, the left internal mammary artery (LIMA) has become the gold standard. Pedicled and skeletonized methods are the two most common harvesting procedures. Objective: In this study we compared between both techniques regarding incidence of postoperative mediastinitis in diabetic patients. Patients and methods: 80 diabetic patients with controlled diabetes i.e. HbA1c below 7 underwent on-pump coronary artery bypass grafting $(\mathrm{CABG})$ surgery were included in this study. The patients were divided into two groups, according to the procedure applied to harvest the LIMA: Group 1: 40 patients underwent pedicled LIMA and Group 2: 40 patients underwent skeletonized LIMA. After CABG surgery, the cases had a 3-month follow-up time. Results: In the pedicled LIMA group, the frequency of excessive intraoperative usage of bone wax was significantly increased. A significant increase was found regarding the occurrence of sternal wound infections (SWI) in the pedicled LIMA group $(22.5 \%)$ versus $(12.5 \%)$ within the skeletonized one, $(\mathrm{P}$-value $=0.003)$. The univariate analysis of the factors related to SWI in all of the studied CABG patients were obesity [OR (95\% CI): $15.61(5.78-42.12), \mathrm{P}<0.001]$, pedicled ITA [OR (95\% CI): 4.3(1.4-12.9), P 0.004], intraoperative excessive use of bone wax [OR (95\% CI): 14.53(6.48-32.56), $\mathrm{P}<0.001$ ], and intraoperative excessive use of diathermy [OR (95\% CI): 17.31(7.55-39.4), P <0.001]. Conclusion: In comparison to pedicled LIMA, skeletonized LIMA in CABG was correlated to reduced occurrence of superficial as well as deep SWI among diabetic patients.
\end{abstract}

Keywords: Internal mammary artery mediastinitis, Pedicled, Skeletonized, Sternal wound infection, CABG.

\section{INTRODUCTION}

In coronary artery disease (CAD), the procedure of coronary artery bypass grafting $(\mathrm{CABG})$ is a commonly acknowledged surgical therapy option. For grafting the left anterior descending (LAD) coronary artery, the left internal mammary artery (LIMA) has become the gold standard, despite the fact that other conduits have been employed in CABG ${ }^{(1)}$. This is owing to the fact that it has a higher ten-year patency rate with minimal or no atherosclerotic alterations ${ }^{(2)}$.

The IMA's impact in clinical application can vary, with different harvesting techniques introducing variation. There are two widely used harvesting methods: pedicled and skeletonized methods. The pedicled technique involves dissecting the artery along with its veins, fascia, adipose tissue, and lymphatics away from the chest wall, while skeletonization involves dissecting the LIMA only far from the wall of the chest ${ }^{(3)}$.

The preferential harvesting technique has indeed been questioned on several occasions, as each technique has its own set of advantages and disadvantages. Skeletonization has some advantages over pedicled LIMA, as skeletonized LIMA is lengthier with superior free flow and lower chest wall ache ${ }^{(4)}$. Skeletonization, on the other hand, is more technically demanding, and hypothetically, gathering the vessel with no adjacent fat might result in a reduction in its long-term resistance because it is exposed to more direct surgical damage ${ }^{(5)}$. The best harvesting technique has been disputed on a regular basis, as each technique has its own set of benefits and drawbacks ${ }^{(4)}$.

The complication profile of the harvesting approach must be taken into account, with a particular focus on the risk of mediastinitis. The diminished sternal vascularization associated with the pedicled method has been linked to increased mediastinitis ${ }^{(6)}$. Skeletonization, on the other hand, preserves sternal microcirculation better, which may be a preventative factor against mediastinitis ${ }^{(7)}$.

Cardiac surgery through median sternotomy can be complicated by mediastinitis, which is a rare but dangerous complication. It has a large socioeconomic impact as well as a high morbidity rate ${ }^{(\mathbf{8 , 9 )}}$. A major problem of coronary artery bypass graft (CABG) surgery is mediastinitis, especially when left internal mammary artery (LIMA) are harvested. The actual mechanism that causes mediastinitis is multifactorial (10). Post-cardiac surgery mediastinitis remains a significant surgical site infections (SSI), particularly in $\mathrm{CABG}$ surgeries with the internal mammary artery graft (11).

According to reports from throughout the world, the incidence of mediastinitis following coronary artery bypass surgery $(\mathrm{CABG})$ is minimal. It is, however, linked to a large rise in postoperative mortality and treatment expenses. Diabetes mellitus and harvesting of the internal mammary artery are the two major risk factors mentioned ${ }^{\left({ }^{(12)}\right.}$.

The aim of this study was to compare between pedicled and skeletonized LIMA harvesting techniques 
in diabetic patients undergoing isolated CABG regarding rate of mediastinitis.

\section{PATIENTS AND METHODS}

This was an observational comparative study that was conducted at the Cardiac Surgery Department, National Heart Institute, Egypt from April 2020 to April 2021. 80 diabetic patients with controlled diabetes i.e., HbA1c below 7 with isolated coronary artery disease underwent on-pump CABG surgery through median sternotomy where the LIMA only was harvested for LAD anastomosis while radial and or saphenous vein graft were utilized for the rest of the coronary arteries. The age of the patients enrolled in this study was ranging from 45 to 65 years.

Patients were assigned to one of two groups, according to the procedure applied to harvest the LIMA: Group 1: 40 patients underwent pedicled LIMA technique, and Group 2: 40 patients underwent skeletonized LIMA technique. After CABG surgery, the patients had 3-month follow-up period.

\section{Ethical approval:}

An approval of the study was obtained from National Heart Institute (Egypt) Academic and Ethical Committee. Every patient signed an informed written consent for acceptance of the operation and participation in the study. This work has been carried out in accordance with The Code of Ethics of the World Medical Association (Declaration of Helsinki) for studies involving humans.

\section{Perioperative Management:}

For CABG surgery, a thorough medical history and physical investigation, as well as routine laboratory tests, including CBC, CRP, liver and kidney function test, $\mathrm{HbA1c}$, blood grouping, coagulation profile, virus screening including hepatitis virus $\mathrm{B}$ and $\mathrm{C}$ as well as HIV. Investigations including echo, ECG, chest X-ray, carotid and bilateral lower limbs arterial duplex as well as bilateral lower limb venous duplex, abdominopelvic ultrasound, C.T chest to exclude Covid 19 affection, as well as coronary angiography study and viability study if needed were also performed.

\section{Operative considerations:}

Under general anesthesia. The operation was done where all patients were given a continuous IV insulin infusion to keep their blood sugar levels between 150 and $200 \mathrm{mg} / \mathrm{dl}$. Patients had on-pump CABG through a median sternotomy, following which the LIMA and the greater saphenous vein were harvested at the same time. Pedicled and skeletonized left internal mammary artery harvesting technique was performed according to Farghaly et al. ${ }^{(7)}$.

\section{Postoperative Management:}

Patients were transferred to surgical intensive care unit (SICU), on mechanical ventilation and closely monitored with serum glucose and control with continuous IV insulin infusion. IV antibiotics were given to patients for up to 5 to 7 days following to surgery.

Follow-up for the patients:

After discharge from the hospital, the patients were followed up at outpatient clinics at 2 weeks 6 weeks, and 3 months intervals.

Oral antibiotics were given for another week. Diabetic patients continued on their preoperative insulin, oral or both regimens. Patients were evaluated for SWI via examination of the sternal instability, wound infection symptoms (erythema, pain, wound discharge and edema), temperature (normal or high), microbiological investigation (if there is wound discharges), and CT scan of the chest (if SWI is suspected and clinical examination alone is insufficient). Laboratory studies including blood tests, and microbiological examination were done. To determine the extent, depth, and localization of the infectious process, imaging techniques such as a chest $\mathrm{X}$-ray and/or a chest CT scan were used.

All of the variables of interest were obtained and divided into preoperative, intraoperative, and postoperative characteristics.

\section{Statistical analysis}

SPSS software was used for statistical analysis. For continuous quantitative variables, data were given as mean \pm standard deviation (SD), while for qualitative variables; data were presented as number and percent. To compare continuous quantitative variables between each two independent groups of data, an unpaired t-test was performed. The Chi-square test or Fisher's exact test were used to compare categorical variables. The odds ratio (OR) and 95 percent confidence intervals (CI) were calculated. P-values $<0.05$ were used to determine significance.

\section{RESULTS}

The demographic features of all $\mathrm{CABG}$ cases are shown in table (1).

Table (1): Demographic characteristics of CABG patient

\begin{tabular}{|c|c|}
\hline Variables & $\begin{array}{c}\text { CABG patients } \\
(n=80)\end{array}$ \\
\hline Age (years, means) & $55.76 \pm 8.26$ \\
\hline \multicolumn{2}{|l|}{ Age } \\
\hline$<55$ years & $(63.75 \%)$ \\
\hline$\geq 55$ years & $(36.25 \%)$ \\
\hline \multicolumn{2}{|l|}{ Sex } \\
\hline Female & $(16.25 \%)$ \\
\hline Male & $(83.75 \%)$ \\
\hline BMI $\left(\mathrm{kg} / \mathrm{m}^{2}\right.$, means $)$ & $28.92 \pm 4.42$ \\
\hline \multicolumn{2}{|c|}{ Obesity $\left(\mathrm{BMI} \geq 30 \mathrm{Kg} / \mathrm{m}^{2}\right)$ : } \\
\hline Obese & $28 \quad(35 \%)$ \\
\hline Non-obese & $52(65 \%)$ \\
\hline
\end{tabular}

BMI: Body mass index 
Table (2) shows that there were no significant differences in the demographic data between the both groups.

Table (2): Pedicle vs skeletonized LIMA: a comparison of demographics

\begin{tabular}{|c|c|c|c|}
\hline Variables & Pedicled $(n=40)$ & Skeletonized $(n=40)$ & P-value \\
\hline Age (years, means) & $55.98 \pm 8.6$ & $54.93 \pm 4.65$ & 0.499 \\
\hline \multicolumn{4}{|l|}{ Age grouping } \\
\hline$<55$ years & $25(62.5 \%)$ & $29(72.5 \%)$ & \multirow{2}{*}{0.34} \\
\hline$\geq 55$ years & $15(37.5 \%)$ & $11(27.5 \%)$ & \\
\hline \multicolumn{4}{|l|}{ Sex } \\
\hline Female & $6(15 \%)$ & $7(17.5 \%)$ & \multirow[t]{2}{*}{0.76} \\
\hline Male & $34(85 \%)$ & $33(82.5 \%)$ & \\
\hline BMI $\left(\mathrm{kg} / \mathrm{m}^{2}\right.$, means $)$ & $28.82 \pm 4.1$ & $29.67 \pm 5.62$ & 0.44 \\
\hline \multicolumn{4}{|c|}{ Obesity $\left(\mathrm{BMI} \geq 30 \mathrm{Kg} / \mathrm{m}^{2}\right)$ : } \\
\hline Obese & $13(32.5 \%)$ & $16(40 \%)$ & \multirow{2}{*}{0.49} \\
\hline Non-obese & $27(67.5 \%)$ & $24(60 \%)$ & \\
\hline
\end{tabular}

As shown in table (3), non-significant differences in the preoperative clinical features were found between the two groups.

Table (3): The comparison of the preoperative clinical features of pedicle and skeletonized

\begin{tabular}{|l|c|c|c|}
\hline \multicolumn{1}{|c|}{ Variables } & Pedicled (n=40) & Skeletonized (n=40) & P-value \\
\hline Still smoking & $5(12.5 \%)$ & $9(22.5 \%)$ & 0.32 \\
\hline Stopped smoking & $35(87.5 \%)$ & $31(77.5 \%)$ & 0.64 \\
\hline COPD & $1(2.5 \%)$ & $2(5 \%)$ & 0.59 \\
\hline Without COPD & $39(97.5 \%)$ & $38(95 \%)$ & 0.75 \\
\hline Ejection fraction: & $37(92.5 \%)$ & $36(90 \%)$ & \multirow{2}{*}{0.88} \\
\hline -Normal & $3(7.5 \%)$ & $4(10 \%)$ & 0.87 \\
\hline \begin{tabular}{l|l|l|} 
- Mo\%) \\
ANGINA Class
\end{tabular} & $3 \pm 0.72$ & $3 \pm 0.68$ & 0.51 \\
\hline ANGINA Class III/IV & $29(72.5 \%)$ & $31(77.5 \%)$ & 0.63 \\
\hline ANGINA Class I/II & $11(27.5 \%)$ & $9(22.5 \%)$ & 0.08 \\
\hline Euro SCORE II & $1.24 \pm 0.61$ & $1.38 \pm 0.57$ & 1 \\
\hline Euro SCORE II>3\% & $1(2.5 \%)$ & $1(2.5 \%)$ & \\
\hline
\end{tabular}

There was no significant differences were present between the two groups regarding bypass time, cross-clamp time, excessive diathermy, and para-midline sternotomy, while in the pedicle LIMA group, the incidence of excessive intraoperative usage of bone wax was significantly increased (Table 4).

Table (4): Comparison of intraoperative parameters between pedicle and skeletonized LIMA

\begin{tabular}{|l|c|c|c|}
\hline \multicolumn{1}{|c|}{ Variables } & Pedicled (n=40) & Skeletonized (n=40) & P-value \\
\hline Bypass time (min): & $96.35 \pm 35.11$ & $101.13 \pm 30.37$ & 0.23 \\
\hline$<120 \mathrm{~min}$ & $31(77.5 \%)$ & $29(72.5 \%)$ & \multirow{2}{*}{0.37} \\
\hline$>120 \mathrm{~min}$ & $9(22.5 \%)$ & $11(27.5 \%)$ & 0.18 \\
\hline Cross-clamp time (min): & $58.01 \pm 22.42$ & $64.54 \pm 63.15$ & \multirow{2}{*}{0.36} \\
\hline$<60 \mathrm{~min}$ & $23(57.5 \%)$ & $22(55 \%)$ & $0.0001^{*}$ \\
\hline$>60 \mathrm{~min}$ & $17(42.5 \%)$ & $18(45 \%)$ & 0.42 \\
\hline Excessive bone wax & $8(20 \%)$ & $1(2.5 \%)$ & 0.07 \\
\hline No excessive bone wax & $32(80 \%)$ & $39(97.5 \%)$ & 0.31 \\
\hline Excessive diathermy & $6(15 \%)$ & $3(7.5 \%)$ & 0.75 \\
\hline No excessive diathermy & $34(85 \%)$ & $37(92.5 \%)$ & \\
\hline Para-midline sternotomy & $2(5 \%)$ & $1(2.5 \%)$ & \\
\hline
\end{tabular}

\section{*: Significant difference}

Table (5) revealed a significant increase in the incidence of sternal wound infections (SWI) in the pedicled LIMA group versus in the skeletonized group. On the other hand, there was no significant differences in postoperative duration of ventilation (in hours), hemodynamics, blood transfusion, arrhythmias, pulmonary complications, renal failure, neurological complications, hospital stay (days) between the both groups. 
Table (5): Comparison of postoperative outcomes and complications between pedicled and skeletonized LIMA

\begin{tabular}{|l|c|c|c|}
\hline \multicolumn{1}{|c|}{ Variables } & Pedicled $(\mathbf{n = 4 0 )}$ & Skeletonized $(\mathbf{n = 4 0})$ & P-value \\
\hline Duration of ventilation (hrs.) & $10.43 \pm 8.45$ & $10.99 \pm 9.06$ & 0.40 \\
\hline Sternal wound infection & $9(22.5 \%)$ & $5(12.5 \%)$ & $0.03 *$ \\
\hline No sternal wound infection & $31(77.5 \%)$ & $35(87.5 \%)$ & 0.20 \\
\hline Blood transfusion & $32(80 \%)$ & $30(75 \%)$ & 0.34 \\
\hline No blood transfusion & $8(20 \%)$ & $10(25 \%)$ & 0.31 \\
\hline Arrhythmias & $2(5 \%)$ & $1(2.5 \%)$ & 0.75 \\
\hline No arrhythmias & $38(95 \%)$ & $39(97.5 \%)$ & 0.25 \\
\hline Pulmonary complications & $2(5 \%)$ & $1(2.5 \%)$ & 0.75 \\
\hline No pulmonary complications & $38(95 \%)$ & $39(97.5 \%)$ & 0.25 \\
\hline Neurological complications & $1(2.5 \%)$ & $1(2.5 \%)$ & 1 \\
\hline No neurological complications & $39(97.5 \%)$ & $39(97.5 \%)$ & 1 \\
\hline Hospital stay (days) & $10.44 \pm 5.13$ & $9.55 \pm 4.55$ & 0.15 \\
\hline
\end{tabular}

*Significant difference

There were insignificant lower frequencies of the occurrence of superficial and deep SWI in the skeletonized IMA group than pedicled IMA (Table 6).

Table 6: Comparison of different forms of sternal wound infection among pedicled and skeletonized LIMA groups

\begin{tabular}{|c|c|c|c|c|}
\hline Type & Pedicled $(n=40)$ & Skeletonized $(n=40)$ & $\begin{array}{c}\text { Total } \\
(\mathbf{n}=\mathbf{8 0})\end{array}$ & P-value \\
\hline Type 1 a & $3(7.5 \%)$ & $2(5 \%)$ & $5(6.25 \%)$ & \multirow{2}{*}{0.76} \\
\hline Type 1 b & $2(5 \%)$ & $2(5 \%)$ & $4(5 \%)$ & \\
\hline Total Superficial SWI & $5(12.5 \%)$ & $4(10 \%)$ & $9(11.25 \%)$ & \\
\hline Type 2 a & $1(2.5 \%)$ & $1(2.5 \%)$ & $2(2.5 \%)$ & \multirow[t]{2}{*}{1} \\
\hline Type 2 b & $1(2.5 \%)$ & $0(0 \%)$ & $1(1.25 \%)$ & \\
\hline Type 3 a & $1(2.5 \%)$ & $0(0 \%)$ & $1(1.25 \%)$ & \multirow[t]{2}{*}{1} \\
\hline Type 3 b & $1(2.5 \%)$ & $0(0 \%)$ & $1(1.25 \%)$ & \\
\hline Total Deep SWI & $4(10 \%)$ & $1(2.5 \%)$ & $5(6.25 \%)$ & \\
\hline
\end{tabular}

In table (7) the factor analysis in univariate form related to SWI in all of the studied CABG patients was shown. The significant risk factors were obesity, pedicled LIMA, intraoperative excessive use of bone wax and intraoperative excessive use of diathermy.

Table (7): Univariate analysis of demographic, preoperative and intraoperative clinical characteristics associated with SWI OR (95\% CI): Odds ratio (95\% Confidence Interval)

\begin{tabular}{|l|c|c|c|c|}
\hline \multicolumn{1}{|c|}{ Type } & $\begin{array}{c}\text { No SWI } \\
(\mathbf{n = 6 6 )}\end{array}$ & $\begin{array}{c}\text { SWI } \\
(\mathbf{n = 1 4})\end{array}$ & P-value & OR (95\% CI) \\
\hline Age $\geq \mathbf{5 5}$ years & $22(33.3 \%)$ & $4(28.6 \%)$ & 0.16 & $1.60(0.78-3.27)$ \\
\hline Female sex & $11(16.6 \%)$ & $2(14.3 \%)$ & 0.79 & $0.86(0.30-2.40)$ \\
\hline Obesity & $21(31.8 \%)$ & $8(57.1 \%)$ & $\mathbf{0 . 0 0 0 1}$ & $15.61(5.78-42.12)$ \\
\hline ANGINA Class III/IV & $54(81.8 \%)$ & $6(42.9 \%)$ & $0.033^{*}$ & $0.64(0.29-1.32)$ \\
\hline Still smoking & $12(18.9 \%)$ & $2(14.3 \%)$ & 0.61 & $1.24(0.50-2)$ \\
\hline COPD & $2(3.0 \%)$ & $1(7.1 \%)$ & 0.75 & $0.93(0.10-7.76)$ \\
\hline $\begin{array}{l}\text { MODERATE EF (40\% to } \\
\text { 50\%) }\end{array}$ & $6(9.1 \%)$ & $1(7.1 \%)$ & 0.69 & $1.21(0.39-3.76)$ \\
\hline Euro SCORE II >3\% & $1(1.6 \%)$ & $1(7.1 \%)$ & 0.054 & $2.60(0.49-13.47)$ \\
\hline Pedicled LIMA & $31(46.96 \%)$ & $9(64.3 \%)$ & $\mathbf{0 . 0 0 4} *$ & $4.3(1.4-12.9)$ \\
\hline Skeletonized LIMA & $35(53.03 \%)$ & $5(35.71 \%)$ & 0.06 & $3.7(1.1-11.8)$ \\
\hline Bypass time $\geq \mathbf{1 2 0}$ min & $16(24.4 \%)$ & $4(28.6 \%)$ & 0.053 & $2.3(1.5-4.67)$ \\
\hline Excessive bone wax & $5(7.6 \%)$ & $4(28.6 \%)$ & $\mathbf{0 . 0 0 0 1} *$ & $14.53(6.48-32.56)$ \\
\hline Excessive diathermy & $4(6.0 \%)$ & $5(35.7 \%)$ & $\mathbf{0 . 0 0 0 1} *$ & $17.31(7.55-39.4)$ \\
\hline Signif & & & \\
\hline
\end{tabular}

*: Significant difference 


\section{DISCUSSION}

CABG surgery is considered one of the most commonly conducted cardiac surgical methods. The IMA is an important part of CABG operation, and the left IMA has long been considered the gold standard for myocardial revascularization due to its greater graft patency in comparison with other conduits. Furthermore, its use leads to a higher percentage of survival and a lower risk of recurrent angina ${ }^{(2)}$.

Post-cardiac surgery mediastinitis or sternal wound infection is a common surgical site infection, and one of the most serious consequences following $\mathrm{CABG}$ particularly in the CABG procedures involving the internal mammary artery graft which can put a major burden on health-care resources ${ }^{(13,14)}$.

Skeletonized and pedicled approaches are two well-known LIMA harvesting methods. While the pedicled technique dissects the artery with its associated lymphatics, veins, adipose tissue, and fascia, skeletonization merely dissects the artery free from wholly adjacent tissues ${ }^{(\mathbf{1 5})}$.

This study compared the effect of pedicled LIMA to skeletonized LIMA regarding mediastinitis or SWI among diabetic patients undergoing $\mathrm{CABG}$. According to the findings of this study, skeletonized IMA possessed advantages of significantly less mediastinitis or SWI $(12.5 \%)$ compared to the pedicled IMA $(22.5 \%)$.

In the same line, Lindblom et al. ${ }^{(16)}$ reported that skeletonized LIMA is thought to have benefits over pedicled LIMA in terms of less sternal devascularization, which could lead to a lower SWI.

To classify SWI in this study, we employed Jones criteria which were used over other classification systems because, anatomically as well as biologically, it is further comprehensive. There were 3 various forms of SWIs explained, involving the infections that are superficial or deep, and were classified based on the basis of the degree of infection involvement of the underlying tissue. It's also easier to utilize because it's based solely on traits discovered during sternal probing. Furthermore, type $3 b$ is physiologically significant since it signifies a person who is systemically unwell as a result of the SWI ${ }^{(17)}$.

As mentioned before, the incidence of SWI after CABG was $22.5 \%$ in pedicled LIMA group, while it was $12.5 \%$ in skeletonized LIMA group, with an overall incidence of $17.5 \%$ amongst the 80 patients included in this study. The incidence of superficial SWI (Jones types 1a and 1b) was about $11.25 \%$, while deep SWI had an incidence of nearly $6.25 \%$. These results were within the superficial and deep levels of SWI that have been reported. The prevalence of superficial SWI was reported to range from 0.5 percent to 12 percent, according to Lindblom et al. ${ }^{(16)}$ and Lazar et al. ${ }^{(18)}$, while despite the advancements in prevention, the prevalence of deep SWI remains high, ranging between 0.5 and $6.8 \%(13,19,20)$.

Skeletonization has been shown to enhance LIMA blood flow and reduce the probability of arterial spasm. As a result, skeletonization may help to lower the risk of postoperative poor cardiac output syndrome ${ }^{(21)}$.
Skeletonized LIMA was linked with less overall superficial and deep SWIs within this research, but the whole SWIs (22.5 percent vs 12.5 percent) was the only statistically significant difference. In addition, despite being non-significant, skeletonization was linked to a shorter duration of ventilation and a shorter hospital stay. Peterson et al. ${ }^{(22)}$ found similar results in a prospective trial of 115 diabetic individuals, with 36 underwent traditional pedicled LIMA and 79 underwent skeletonized LIMA. Skeletonization was linked to a reduction in the overall as well as deep SWIs. Likewise, Farghaly et al. ${ }^{(7)}$ who performed a study on 300 patients with coronary artery disease underwent CABG surgery with 200 patients underwent pedicled LIMA, and 100 patients with skeletonized LIMA, also reported that patients with skeletonized LIMA revealed a significant lesser SWI occurrence than patients with pedicled LIMA.

Furthermore, Saso et al. (3) showed that skeletonization was related to a favorable reduction in the odds ratio of SWI in a meta-analysis of thirty three studies was published in 2010. Other studies that looked at the impacts of grafting of LIMA on problems that could occur postoperatively, applying the pedicled versus skeletonized approach, found similar results. In a meta-analysis on twenty-two investigations including 4817 cases (2393 pedicled; 2424 skeletonized), Sá and colleagues ${ }^{(15)}$ found that the occurrence of SWI postoperatively decreased when skeletonized LIMA was applied compared to pedicled LIMA. Similarly, Fouquet et al. ${ }^{(23)}$ found that skeletonization resulted in lesser wound infections, less pain in chest, in addition to a smaller hospitalization period.

The pedicled technique is the most usual method of harvesting LIMA; however, it can result in catastrophic sternal devascularization. As the sternal ischemia is a great contributor to the SWI pathophysiology, skeletonized IMA has been advocated as a substitute approach for preserving sternal vascularity ${ }^{(24)}$.

Other researchers, on the other hand, were in disagreement with the findings of this study, as they found no difference in sternal blood flow between pedicled and skeletonized grafts ${ }^{(25)}$. This disagreement could indicate that additional variables, unrelated to the harvesting procedure, decreased blood flow and contributed to the development of SWIs after IMA harvesting.

Within this study, in CABG patients with pedicled LIMA, obesity, diabetes mellitus, excessive bone wax, and excessive diathermy were identified to be risk factors for mediastinitis. Owing to the greater preservation of collateral sternal blood flow and internal thoracic veins, the skeletonized LIMA approach has been shown to lower the occurrence of deep mediastinitis, especially in individuals who are diabetic or obese ${ }^{(22)}$. These results were in agreement with Farghaly $\boldsymbol{e t}$ al. ${ }^{(7)}$ and Peterson et al. ${ }^{(22)}$.

\section{CONCLUSION}

From the findings of this study, it is concluded that, in comparison to pedicled LIMA, skeletonized LIMA in 
CABG was linked with reduced occurrence of superficial as well as deep SWI. In addition, pedicled LIMA, diabetes mellitus, obesity, excessive bone wax, and the excessive diathermy usage for hemostasis might all play a role in increased incidence of mediastinitis with the pedicled technique. In individuals who are at greater risk like those with diabetes or obesity, skeletonized approach might be of choice.

Financial support and sponsorship: Nil.

Conflict of interest: Nil.

\section{REFERENCES}

1. Gaughan J, Kobel C (2014): Coronary artery bypass grafts and diagnosis related groups: patient classification and hospital reimbursement in 10 European countries. Health Economics Review, 4(1): 1-13.

2. Bakaeen F (2017): CABG: A continuing evolution. Cleveland Clinic Journal of Medicine, 84(12): 15-19.

3. Saso S, James D, Vecht $\mathbf{J}$ et al. (2010): Effect of skeletonization of the internal thoracic artery for coronary revascularization on the incidence of sternal wound infection. The Annals of Thoracic Surgery, 89(2): 661-670.

4. Mannacio V, Di Tommaso L, De Amicis et al. (2011): Randomized flow capacity comparison of skeletonized and pedicled left internal mammary artery. The Annals of Thoracic Surgery, 91(1): 24-30.

5. Hu X, Zhao Q (2011): Skeletonized internal thoracic artery harvest improves prognosis in high-risk population after coronary artery bypass surgery for good quality grafts. The Annals of Thoracic Surgery, 92(1): 48-58.

6. Raja S, Dreyfus G (2005): Internal thoracic artery: to skeletonize or not to skeletonize?. The Annals of Thoracic Surgery, 79(5): 1805-1811.

7. Farghaly A, Nady M, Elminshawy A (2020): Skeletonized versus pedicled left internal mammary artery harvesting and risk of sternal wound infection after coronary artery bypass surgery. The Egyptian Cardiothoracic Surgeon, 2(4): 126-133.

8. Diez C, Koch D, Kuss O et al. (2007): Risk factors for mediastinitis after cardiac surgery-a retrospective analysis of 1700 patients. Journal of Cardiothoracic Surgery, 2(1): 1-8.

9. de Oliveira S, Soares E, Santos C et al. (2011): Risk factors for mediastinitis after coronary artery bypass grafting surgery. Rev Bras Cir Cardiovasc., 26(1): 27-35.

10. Tavolacci $M$, Merle $V$, Josset $V$ et al. (2003): Mediastinitis after coronary artery bypass graft surgery: influence of the mammary grafting for diabetic patients. Journal of Hospital Infection, 55(1): 21-25.

11. Silva Q, Canini S, Silveira R et al. (2015): Risk factors for mediastinitis after coronary artery bypass grafting surgery: an integrative review. REME-Rev Min Enferm., 19(4): 1015-22.

12. Lenz K, Brandt M, Fraund-Cremer S et al. (2016): Coronary artery bypass surgery in diabetic patients-risk factors for sternal wound infections. GMS
Interdisciplinary plastic and reconstructive surgery DGPW., 5: 18-23.

13. Cotogni P, Barbero C, Rinaldi M (2015): Deep sternal wound infection after cardiac surgery: evidences and controversies. World Journal of Critical Care Medicine, 4(4): 265-68.

14. Sajja L (2015): Strategies to reduce deep sternal wound infection after bilateral internal mammary artery grafting. International Journal of Surgery, 16: 171-178.

15. Sá M, Ferraz P, Escobar R et al. (2013): Skeletonized versus pedicled internal thoracic artery and risk of sternal wound infection after coronary bypass surgery: metaanalysis and meta-regression of 4817 patients. Interactive Cardiovascular and Thoracic Surgery, 16(6): 849-857.

16. Lindblom R, Lytsy B, Sandström $C$ et al. (2015): Outcomes following the implementation of a quality control campaign to decrease sternal wound infections after coronary artery by-pass grafting. BMC Cardiovascular Disorders, 15(1): 1-9.

17. Jones G, Jurkiewicz M, Bostwick J et al. (1997): Management of the infected median sternotomy wound with muscle flaps. The Emory 20-year experience. Annals of Surgery, 225(6): 766-71.

18. Lazar H, Salm T, Engelman R et al. (2016): Prevention and management of sternal wound infections. J Thorac Cardiovasc Surg., 152 (4): 962-72.

19. Lemaignen $A$, Birgand $G$, Ghodhbane $W$ et al. (2015): Sternal wound infection after cardiac surgery: incidence and risk factors according to clinical presentation. Clinical Microbiology and Infection, 21(7): 674-79.

20. Litwinowicz R, Bryndza M, Chrapusta A et al. (2016): Hyperbaric oxygen therapy as additional treatment in deep sternal wound infections-a single center's experience. Polish Journal of Thoracic and Cardiovascular Surgery, 13(3): 198-202.

21. Lazar H (2018): The risk of mediastinitis and deep sternal wound infections with single and bilateral, pedicled and skeletonized internal thoracic arteries. Annals of Cardiothoracic Surgery, 7(5): 663672.

22. Peterson $M$, Borger $M$, Rao $V$ et al. (2003): Skeletonization of bilateral internal thoracic artery grafts lowers the risk of sternal infection in patients with diabetes. The Journal of Thoracic and Cardiovascular Surgery, 126(5): 1314-1319.

23. Fouquet O, Tariel F, Desulauze P et al. (2015): Does a skeletonized internal thoracic artery give fewer postoperative complications than a pedicled artery for patients undergoing coronary artery bypass grafting? Interactive Cardiovascular and Thoracic Surgery, 20(5): 663-668.

24. De Paulis R, de Notaris S, Scaffa $R$ et al. (2005): The effect of bilateral internal thoracic artery harvesting on superficial and deep sternal infection: the role of skeletonization. The Journal of Thoracic and Cardiovascular Surgery, 129(3): 536-543.

25. Nishi H, Mitsuno M, Tanaka $H$ et al. (2010): Decreasing sternum microcirculation after harvesting the internal thoracic artery. European Journal of CardioThoracic Surgery, 40(1): 240-244. 